\title{
TWO COMPONENTS FROM EYE TISSUE THAT DIFFERENTIALLY STIMULATE THE GROWTH AND DEVELOPMENT OF CILIARY GANGLION NEURONS IN CELL CULTURE ${ }^{1}$
}

\author{
RAE NISHI ${ }^{2}$ AND DARWIN K. BERG ${ }^{3}$ \\ Department of Biology, University of California, San Diego, La Jolla, California 92093
}

\begin{abstract}
Survival and development of chick ciliary ganglion neurons in vivo appear to depend on information from the embryonic eye structure that contains the postsynaptic targets of the neurons. We have tested embryonic eye extracts on ciliary ganglion neurons in dissociated cell culture for stimulation of growth and development. Control conditions were chosen that permitted the long term maintenance of the neurons in the absence of tissue extracts or conditioned medium. The conditions included coating the culture substratum with fibroblast material and increasing the $\mathrm{K}^{+}$ concentration in the culture medium to $25 \mathrm{~mm}$. Neurons survived for at least 3 weeks in control conditions.

Two major components were resolved in eye extracts that stimulated growth and development of the neurons above the basal levels obtained with control conditions. One component, with an apparent molecular weight of about $2 \times 10^{4}$ by gel filtration analysis, stimulated neuronal growth without increasing the levels of choline acetyltransferase activity per neuron. The second component, with an apparent molecular weight of about $5 \times 10^{4}$, increased development of choline acetyltransferase levels per neuron but had no effect on neuronal growth. Both components were effective in normal $\mathrm{K}^{+}$as well as $25 \mathrm{~mm} \mathrm{~K}$. These components may represent mechanisms by which the postsynaptic target tissue acts in vivo to direct the growth and development of ciliary ganglion neurons.
\end{abstract}

Neuronal development has been shown, in many cases, to depend on information from the tissue innervated by the neurons. Classic studies by Hamburger and LeviMontalcini (1949) showed that extirpation of the wing bud of embryonic chickens early in development led to degeneration of the sensory and motoneurons that normally innervated the missing limb. Enlargement of the periphery by the addition of another limb reduced the amount of naturally occurring neuron loss (Hollyday and Hamburger, 1976). Similar observations have been reported for other neuronal populations both in the central and peripheral nervous systems (Cowan, 1973).

It has been widely suggested that the target tissue provides a "trophic factor" that is required by the neurons for continued survival and development. The only putative trophic factor that has been isolated to date is nerve growth factor (NGF), first described by Levi-Montalcini and Hamburger (1953) and subsequently purified

\footnotetext{
1 This work was supported by grants from the National Institutes of Health (NS 12601 and 5T32GM07313) and from the Muscular Dystrophy Association.

${ }^{2}$ Current address: Department of Neurobiology, Harvard Medical School, 25 Shattuck Street, Boston, MA 02115.

${ }^{3}$ To whom correspondence should be addressed.
}

to homogeneity (Cohen, 1959; Varon et al., 1967). NGF has been shown to enhance the survival and development of sensory and sympathetic neurons both in vivo and in cell culture. A number of lines of evidence suggest that NGF may serve as a trophic factor for sensory and sympathetic neurons (Greene and Shooter, 1980). Clearly, models of neuronal development based on the existence of trophic factors would be much strengthened if similar components could be identified which served other neuronal populations.

An attractive system for identifying other trophic factor candidates is the chick ciliary ganglion $(\mathrm{CG})$, a parasympathetic ganglion that is not responsive to NGF. The chick CG contains two major populations of neurons, both of which are cholinergic and innervate exclusively structures in the eye. The ciliary neurons innervate striated muscle in the iris and ciliary body, while the choroid neurons innervate smooth muscle in the choroid layer. Landmesser and Pilar (1.974a) showed that about half of the neurons in each population die between days 8 and 14 in the embryo, reducing the total number of ganglionic neurons from 6500 to 3200 . Survival of CG neurons after embryonic day 8 appears to depend on information from the tissue innervated by them. The period of cell death in the ganglion coincides with the 
time when the neurons form synapses on muscle cells in the periphery (Landmesser and Pilar, 1978). Removal of the optic vesicle prior to the period of neuron death causes nearly all of the neurons to die (Landmesser and Pilar, 1974b).

Recently, it has become possible to study the survival and development of CG neurons in dissociated cell culture (Helfand et al., 1976). Nearly all of the CG neurons present in 8-day embryos survive for weeks in cell culture, though half of the neurons would have died in vivo within 6 days (Nishi and Berg, 1977). The neurons develop high levels of choline acetyltransferase (CAT) activity in culture (Nishi and Berg, 1979), and many of them form functional synapses on myotubes in mixed nerve-muscle cultures (Nishi and Berg, 1977). Survival and development of CG neurons grown on standard substrata, such as collagen or polyornithine, appear to require culture media supplemented with tissue extracts or cell conditioning (Helfand et al., 1976; Nishi and Berg, 1979; Varon et al., 1979; Tuttle et al., 1980). NGF will not substitute for the extracts or cell conditioning (Helfand et al., 1976; Nishi, 1980). It is possible that the extracts and conditioned medium supply components normally required by the neurons in vivo and that the components are produced in vivo by the postsynaptic tissue though in limiting amounts.

We have used a cell culture assay to characterize components in tissue extracts that stimulate the growth and development of CG neurons. For this approach, culture modifications were devised which permitted the long term maintenance of CG neurons in control cultures in the absence of extracts or conditioned medium. The modifications included the use of fibroblast material as a culture substratum and the inclusion of high concentrations of $\mathrm{K}^{+}$in the medium. Extracts prepared from embryonic eye tissue then were tested for components which stimulated growth and development of the neurons above the basal levels obtained in control cultures. Two components were identified: One component stimulated ncuronal growth without affecting levels of CAT activity, while the other component stimulated development of CAT levels without affecting neuronal growth.

\section{Materials and Methods}

Preparation of cell cultures. Ciliary ganglia from $7 \frac{1}{2-}$ day (stage 32 to 33; Hamburger and Hamilton, 1951) chick embryos were removed and dissociated into a suspension of single cells as previously described (Nishi and Berg, 1977). The volume of the suspension was adjusted to yield one ganglion equivalent of cells per $0.1 \mathrm{ml}$. Cells were plated at one ganglion equivalent per $16-\mathrm{mm}$ Falcon tissue culture well (No. 3008). Culture wells were coated with collagen as previously described (Fischbach, 1972). For experiments in which neurons were grown on fibroblast material, the cultures first were seeded with fibroblasts obtained by trypsin dissociation of embryonic chick skin tissue. The fibroblasts were grown to confluency ( 2 to 3 days), washed three times with distilled water, and then incubated in water for 1 to $2 \mathrm{hr}$. This procedure caused all of the fibroblasts to expand and lyse. The cultures then were rinsed once with Earle's balanced salt solution (BSS) and seeded with neurons.
Media and chemicals. Simple culture medium for neurons consisted of Eagle's minimal essential medium (MEM) supplemented with $10 \%(\mathrm{v} / \mathrm{v})$ heat-inactivated horse serum, 50 units $/ \mathrm{ml}$ of penicillin, and $50 \mu \mathrm{g} / \mathrm{ml}$ of streptomycin. Fibroblasts were grown in medium containing $10 \%(\mathrm{v} / \mathrm{v})$ fetal bovine serum in place of the horse serum. Neurons were fed every 2 to 3 days. Few nonneuronal cells developed in neuron cultures under any of the growth conditions used in this study.

Eye extract was prepared from 17-day (HamburgerHamilton stage 44) chick embryos. The eyes were removed and the vitreous humor and lens were discarded. The remaining structures were minced and homogenized in a volume corresponding to $1 \mathrm{ml}$ per eye in $2 \mathrm{~mm}$ sodium phosphate, $\mathrm{pH} 7.5$, with $0.14 \mathrm{M}$ sodium chloride (PBS). The homogenate was incubated at $4^{\circ} \mathrm{C}$ for 1 to 15 $\mathrm{hr}$ and then centrifuged at 27,000 $\times \mathrm{g}$ for $90 \mathrm{~min}$. The supernatant fraction was removed and passed through a $0.2-\mathrm{mm}$ Millipore filter for sterilization. The protein concentration was usually in the range of 2.3 to $2.6 \mathrm{mg} / \mathrm{ml}$. The length of incubation at $4^{\circ} \mathrm{C}$ had little effect on the final activity of the extract.

The potassium concentration of the medium was elevated by diluting a solution of $0.2 \mathrm{M} \mathrm{KCl}$ into the medium to yield a final concentration of $25 \mathrm{~mm} \mathrm{~K}$. This produced a small increase $(3 \%)$ in the osmolarity of the medium and a small dilution of the other components. A comparable dilution with $0.2 \mathrm{M} \mathrm{NaCl}$ had no effect on neuronal survival, indicating that the $\mathrm{K}^{+}$effect could not be attributed to these changes.

MEM, Earle's BSS, horse serum, fetal bovine serum, glutamine, penicillin, streptomycin, and crude trypsin were purchased from Microbiological Associates. Horse serum was heat-inactivated by incubation at $56^{\circ} \mathrm{C}$ for 30 $\min .\left[{ }^{3} \mathrm{H}\right]$ Acetylcoenzyme A (specific activity of 1.9 to 7 $\mathrm{Ci} / \mathrm{mmol}$ ) and a mixture of ${ }^{3} \mathrm{H}$-amino-acids (specific activity of $16.7 \mathrm{mCi} / \mathrm{mg}$ ) were purchased from ICN. Acetylcholine chloride (ACh), tetraphenylboron, sodium pyruvate, NADH, and trichloroacetic acid (TCA) were purchased from Sigma. P. Ravdin (University of Miami School of Medicine) purified $7 \mathrm{~S} \mathrm{NGF}$ according to the method of Burton et al. (1978), and $\beta$-NGF was isolated from it by ion exchange chromatography (Varon et al., 1968)

Cell counts and measurements. Neuronal cell counts were obtained by examining 15 fields of view per culture at $\times 200$ magnification. The fields were spaced evenly across the culture and represented $3.3 \%$ of the total surface area. The culture conditions usually resulted in a uniform distribution of neurons on the substratum; cultures with an obvious non-uniform distribution were discarded. Neuronal cell diameters were measured with an ocular micrometer that was calibrated with a slide micrometer. Soma volumes then were calculated by assuming them to be spheres.

Choline acetyltransferase assays. Choline acetyltransferase (CAT) activity was assayed by measuring the synthesis of $\left[{ }^{3} \mathrm{H}\right] \mathrm{ACh}$ from $\left[{ }^{3} \mathrm{H}\right]$ acetylcoenzyme A (AcCoA) using the method described by Fonnum (1969) as modified by Berg and Fischbach (1978). Carrier-free $\left[{ }^{3} \mathrm{H}\right] \mathrm{AcCl}$ A was purified by passage over Dowex $50 \mathrm{~W}-\mathrm{X} 8$ (Schrier and Schuster, 1967) and was mixed with unla- 
beled AcCoA to give a specific activity of $0.3 \mathrm{Ci} / \mathrm{mmol}$. Reactions were carried out for $20 \mathrm{~min}$ at $37^{\circ} \mathrm{C}$. Assays were linear with enzyme concentration over the range examined ( 7 to $363 \mathrm{pmol}$ of $\mathrm{ACh} / \mathrm{hr} /$ assay). ACh synthesis was not strictly linear with time over the entire 20 min incubation period, but corrections for nonlinearity were small $(<10 \%)$ and were independent of enzyme concentration. Background, determined by omitting enzyme, represented about $0.1 \%$ of the total radioactivity in the assay and was equivalent to 1 to $10 \%$ of the $\left[{ }^{3} \mathrm{H}\right]$ ACh synthesized with the enzyme concentrations used. Fibroblast extracts contained no detectable activity over background. Naphthylvinyl pyridine $(0.5 \mathrm{~mm})$, a specific inhibitor of CAT activity (White and Cavallito, 1970), inhibited at least $80 \%$ of the activity in CG culture extracts. One unit of CAT activity is defined as the synthesis of $1 \mathrm{nmol}$ of ACh per hr.

Lactate dehydrogenase assays. Lactate dehydrogenase (LDH) activity was assayed in aliquots taken from the same culture extracts used for CAT assays. LDH activity was measured spectrophotometrically by following the conversion of NADH to NAD in the presence of pyruvate and enzyme at room temperature. One unit of $\mathrm{LDH}$ activity is defined as a decrease of 1 unit per min in the absorbance of light at $340 \mathrm{~nm}$ using a path length of $1 \mathrm{~cm}$.

Protein determinations. Protein was measured by the method of Lowry et al. (1951), using bovine serum albumin as a standard.

Protein synthesis. The rate of protein synthesis was measured in cell culture by following the conversion of ${ }^{3} \mathrm{H}$-amino-acids into acid-insoluble material. Cultures were rinsed twice with $\mathrm{PBS}$ and incubated at $37^{\circ} \mathrm{C}$ in 0.3 $\mathrm{ml}$ of Earle's BSS containing MEM vitamins and 10 to $20 \mathrm{Ci} / \mathrm{ml}$ of ${ }^{3} \mathrm{H}$-amino-acids. The cultures then were rinsed three times, lysed with $0.10 \mathrm{ml}$ of distilled water, and, after $1 \mathrm{~min}$, scraped in $0.10 \mathrm{ml}$ of $20 \%$ TCA. An additional $0.10 \mathrm{ml}$ of $10 \%$ TCA was used to rinse the cultures. The extract and rinse solutions were pooled, incubated overnight at $4^{\circ} \mathrm{C}$, and centrifuged 5 min at $15,600 \times g$. The acid-insoluble fraction was rinsed once with $0.2 \mathrm{ml}$ of $10 \%$ TCA and then dissolved in $0.20 \mathrm{ml}$ of $0.6 \mathrm{~N} \mathrm{NaOH}$. After $4 \mathrm{hr}$, an aliquot was acidified and counted in Aquasol-2 in a scintillation counter to determine the amount of acid-insoluble radioactivity. An aliquot of the first supernatant fraction also was counted to determine the acid-soluble radioactivity associated with the cells. Label in the acid-soluble fraction reached a maximum within $2 \mathrm{hr}$, indicating the intracellular pools of free amino acids had been saturated. Incorporation of radioactivity into the acid-insoluble fraction continued linearly for at least $7 \mathrm{hr}$. An incubation period of $4 \mathrm{hr}$ was used to compare relative rates of protein synthesis among cultures.

\section{Results}

Long term maintenance of neurons. Two modifications of the standard culture conditions were used to obtain long term maintenance of ciliary ganglion (CG) neurons in the absence of conditioned medium or tissue extracts. The first was the use of fibroblast material to coat the collagen substratum. Almost all of the neurons present in $7 \frac{1}{2}$-day-old embryonic ciliary ganglia survived for at least 6 days in simple medium when grown on the fibroblast substratum (Fig. 1). In contrast, few neurons $(<10 \%)$ could be identified in culture after 2 to 3 days when the cells were plated in simple medium on a plain collagen substratum.

The second modification used to promote neuronal survival was the addition of $\mathrm{KCl}$ to the culture medium to increase the $\mathrm{K}^{+}$concentration to $25 \mathrm{~mm}$. Neuronal survival on the fibroblast substratum with simple medium containing $25 \mathrm{mM} \mathrm{K}^{+}$was extended to several weeks (Fig. 1) and was indistinguishable from that found with a complex medium (embryo extract and cell conditioning) on a collagen substratum (Nishi and Berg, 1979). Growth and development of the neurons proceeded very slowly under these basal conditions (see below). Elevated $\mathrm{K}^{+}$levels also extended the survival of neurons in simple medium on plain collagen substrata, but greater variability was observed after 1 week. In all subsequent experiments, neurons were grown on a fibroblast substratum with simple medium containing $25 \mathrm{~mm} \mathrm{~K}^{+}$(basal conditions) unless otherwise indicated.

Effects of eye extract. Since eye tissue contains all of the synaptic targets for CG neurons in vivo, it is a likely source for components that stimulate the growth and development of CG neurons. The effect of embryonic eye extract on CG neurons was tested first by growing the neurons in the extract for periods up to 3 weeks and assaying them for choline acetyltransferase (CAT) activity. The extract produced a 2 - to 4 -fold increase in CAT levels compared to control conditions (Fig. 2). 'The increased CAT levels paralleled those previously reported for a complex medium prepared by cell conditioning and supplemented with embryo extract (Nishi and Berg, 1979). Brief exposure to eye extract was not adequate to sustain full development of CAT levels: Neurons incubated in extract for 1 day and then returned to control conditions for 10 days had only about one-half of the CAT activity of neurons maintained in extract for the full 11 days.

Titration experiments were carried out to determine

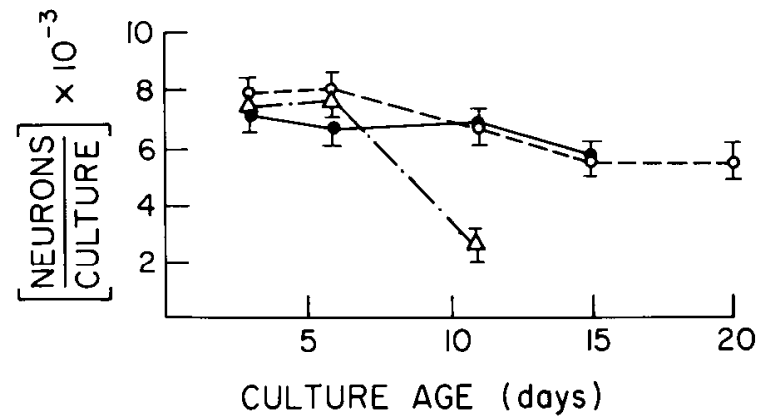

Figure 1. Survival of ciliary ganglion neurons under control conditions. Ciliary ganglion neurons were grown on culture substrata coated with fibroblast material and fed with simple medium containing either $5.6 \mathrm{mM} \mathrm{K}^{+}\left(\triangle-\cdot-\triangle\right.$ or $25 \mathrm{mM} \mathrm{K}^{+}$ $\left(\mathrm{O}_{--} \mathrm{O}\right)$. Data reported previously for neurons grown on a plain collagen substratum with conditioned medium and embryo extract (Nishi and Berg, 1979) are re-plotted here for comparison (-). Values represent the mean of 3 to 10 cultures from one to four separate experiments; bars indicate the SEM. 


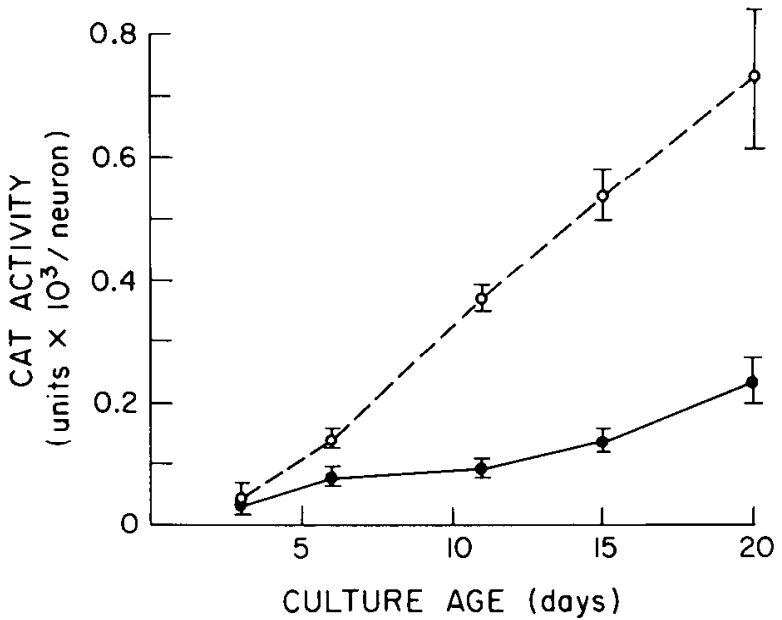

Figure 2. Stimulation of CAT levels per neuron by eye extract. Neurons were grown on substrata coated with fibroblast material and fed with simple medium containing $25 \mathrm{mM} \mathrm{K}^{+}$ (basal conditions) (-) or the same medium supplemented with $5 \%(v / v)$ eye extract $\left(\mathrm{O}_{-}-\mathrm{O}\right)$. Cell counts and CAT assays were performed on the same cultures. Values represent the mean of 4 to 18 cultures pooled from three to nine experiments; bars indicate the SEM.

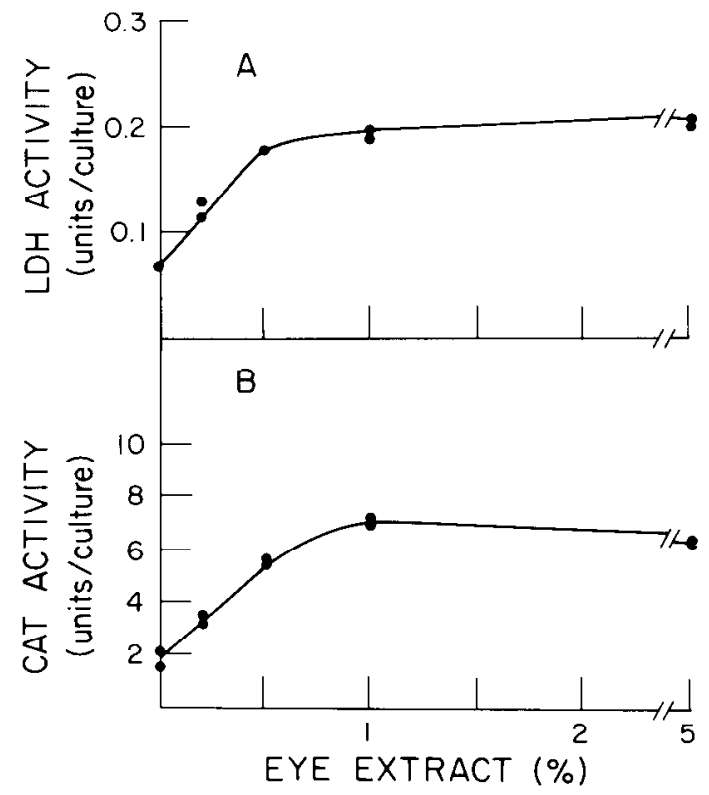

Figure 3. Dependence of CAT and LDH levels on the concentration of eye extract. Neurons were grown in basal conditions (Fig. 2) with the indicated concentrations of eye extract. After 9 days, the cultures were assayed $(A)$ for LDH activity and $(B)$ for CAT activity. Each point represents a single culture.

the concentration of eye extract necessary for maximum development of CAT activity. Lactate dehydrogenase (LDH) activity was assayed as a marker for cell growth since it is a ubiquitous cytoplasmic enzyme. Few nonneuronal cells were present in the cultures under any of the conditions tested, rendering LDH a reliable indicator of neuronal cytoplasm in these cases (see below). Protein determinations were not useful because of the large contribution from the fibroblast material attached to the substratum. Extract concentrations of $1 \%$ (about $25 \mu \mathrm{g}$ / ml) produced a maximum stimulation of both CAT and LDH levels in cultures examined after 9 days (Fig. 3). For subsequent experiments, a unit of stimulatory activity was defined as the amount of stimulation required to increase CAT levels (CAT-stimulating activity) or LDH levels (growth-promoting activity) to one-half of the maximum increment caused by saturating amounts of eye extract. For each series of assays, a "dose-response" curve was generated by including a range of eye extract concentrations; samples to be tested (e.g., column fractions) were diluted appropriately to yield a response within the linear range of the assay.

Fractionation of eye extract. Eye extract was fractionated by gel filtration to characterize components influencing the growth and development of CG neurons in culture. Two major peaks of activity were resolved (Fig. 4). One activity, with an apparent molecular weight of about $2 \times 10^{4}$, stimulated neuronal growth but had no effect on levels of CAT activity. This was termed growthpromoting activity (GPA). A second peak of activity,

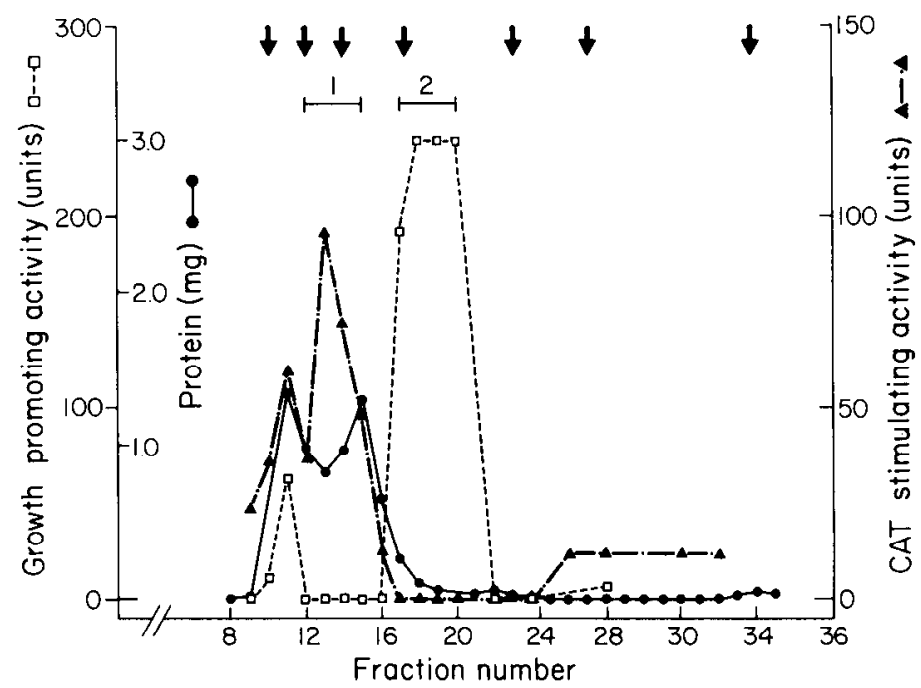

Figure 4. Fractionation of eye extract by filtration through Bio-Gel P-200. Eye extract $(3 \mathrm{ml})$ was applied to a Bio-Gel P. 200 column $(105 \mathrm{ml} ; 1.8 \times 35 \mathrm{~cm})$ equilibrated with $\mathrm{PBS}$ at $4^{\circ} \mathrm{C}$. Fractions $(3 \mathrm{ml})$ were collected, measured for protein, and tested for effects on CG neurons by growing cultures in basal conditions (Fig. 2) supplemented with diluted aliquots from the fractions and then assaying the cultures for LDH activity, CAT activity, and number of surviving neurons as described in Figure 3. To calculate units of stimulatory activity, cultures also were grown in a range of eye extract concentrations $(0$ to $5 \% \mathrm{v} / \mathrm{v})$ and assayed for CAT and LDH activities to construct a "doseresponse" curve. Column fraction dilutions were chosen to yield responses estimated to be in the linear range of the assay; actual volumes assayed were the same in all cases. A unit of growthpromoting activity (GPA) was defined as the amount of stimulation necessary to produce half of the maximum increment in LDH levels caused by eye extract; a unit of CAT-stimulating activity (CSA) was defined in the same way with respect to CAT levels. The horizontal bars indicate fractions pooled for CSA ( pool 1) and GPA ( pool 2). The arrows from left to right indicate the elution positions for Blue dextran $(200,000)$, human transferrin $(80,000)$, ovalbumin $(40,000)$; soybean trypsin inhibitor $(26,000)$, cytochrome $c(13,500), \alpha$-bungarotoxin $(8,000)$, and $\left[{ }^{3} \mathrm{H}\right]$ choline chloride (140). The elution position of Blue dextran marks the void volume of the column, while $\left[{ }^{3} \mathrm{H}\right]-$ choline chloride indicates the completely included volume. 
TABLE I

Recoveries after fractionation of eye extract

Pooled fractions (pools 1 and 2) and starting sample (extract) from the Bio-Gel P-200 column shown in Figure 4 were assayed for protein, GPA, and CSA. Units of activity were calculated as described in Figure 4. Total recoveries for all column fractions were $75 \%$ for protein, $75 \%$ for GPA-like activity, and $72 \%$ for CSA-like activity. Extract values have been defined as $100 \%$.

\begin{tabular}{|c|c|c|c|c|c|c|c|c|}
\hline \multirow[t]{2}{*}{ Sample } & \multicolumn{2}{|c|}{ Protein } & \multicolumn{3}{|c|}{ GPA } & \multicolumn{3}{|c|}{ CSA } \\
\hline & $m g$ & \% recov. & units & \% recov. & units $/ m g$ & units & \% recov. & units/mg \\
\hline Extract & 9.9 & 100 & 1500 & 100 & 150 & 600 & 100 & 60 \\
\hline Pool 1 & 4.0 & 40 & 0 & 0 & 0 & 252 & 42 & 63 \\
\hline Pool 2 & 0.4 & 4 & 912 & 61 & 2280 & 0 & 0 & 0 \\
\hline
\end{tabular}

with an apparent molecular weight of about $5 \times 10^{4}$, stimulated development of CAT levels but had no effect on neuronal growth. This second activity was termed CAT-stimulating activity (CSA). Resolution of GPA and CSA by gel filtration was very reproducible; similar results were obtained with eight different preparations of eye extract. In some cases, small amounts of both kinds of activities were found in the excluded volume of the $\mathrm{P}$. 200 column (Fig. 4). It is not clear whether the material was unique or simply represented aggregated GPA and CSA. Similarly, sometimes material was recovered near the completely included volume of the column that produced a small increase in the development of CAT levels (Fig. 4).

For the characterization of GPA and CSA, fractions containing the peak activities from the column were pooled in each case (Fig. 4). Recoveries for the pooled fractions are shown in Table I. The proportion of GPA recovered was routinely high and similar to the proportion of total protein recovered from the column. The specific activity of the GPA pool varied considerably among columns depending on the amount of overlap between the GPA peak and a major peak of protein. Purifications of 3- to 15-fold were calculated for GPA pools from different columns. Recovery of CSA in pooled fractions was somewhat lower for two reasons. CSA-like activity present in other regions of the column was excluded from the pooled fractions, and, as will be shown below, CSA requires some GPA for maximum effect. Specific activities of the CSA pool were equivalent to that for eye extract.

Characterization of GPA. GPA pools stimulated neuronal growth to the same maximum extent that eye extract did. This was shown by growing neurons in different concentrations of GPA for 9 days and assaying them for LDH activity (Fig. 5). GPA had no effect on development of CAT levels, expressed as CAT activity per neuron, over the entire range of GPA concentrations tested ( 0 to $10 \%, v / v)$.

Other aspects of neuronal growth were measured to determine whether LDH levels served as an adequate marker in this regard. Cell diameters were measured to calculate the mean soma volume for neurons grown under different conditions. Relative rates of protein synthesis by the neurons were examined by following the conversion of radioactive amino acids into acid-insoluble material. By both criteria, GPA stimulated an increase in neuronal growth, and the amount of increase was similar to that indicated by LDH levels (Table II).

Characterization of CSA. CSA stimulated development of CAT levels without increasing neuronal growth,

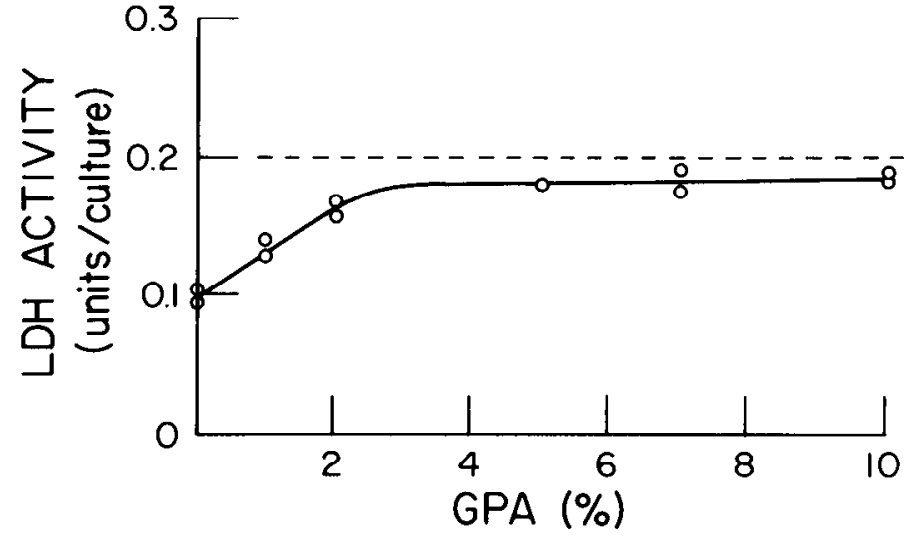

Figure 5. Dependence of LDH levels on GPA concentration. Neurons were grown in basal conditions with the indicated concentrations (v/v) of GPA ( pool 2, Fig. 4) for 9 days and then assayed for LDH activity. Each point represents a single culture. The dotted line indicates the level of $\mathrm{LDH}$ activity obtained with $5 \%(\mathrm{v} / \mathrm{v})$ eye extract. Cultures receiving 0 and $10 \%$ GPA also were assayed for CAT activity and were found to have equivalent amounts.

but the maximum levels of CAT induced by CSA alone were less than those obtained with eye extract (Fig. 6). Though GPA did not itself stimulate CAT development, it did influence the response of the neurons to CSA. This was shown by growing neurons in a range of CSA concentrations for each of two GPA concentrations. Cultures receiving the higher GPA concentration consistently developed more CAT activity and, at the highest concentrations of CSA and GPA, approached the maximum CAT levels obtained with eye extract (Fig. 7).

The different roles of GPA and CSA were clearly reflected in the levels of CAT specific activity, i.e., CAT/ LDH, generated by the neurons. Since GPA stimulated growth without changing the amount of CAT per neuron, CAT specific activity was actually lower for neurons in GPA than in eye extract (Table III). CSA stimulated development of CAT activity without changing neuronal growth and, as a result, induced CAT specific activities significantly higher than did eye extract. Finally, CSA and GPA combined stimulated both CAT and LDH levels with a resultant CAT specific activity equivalent to that obtained with eye extract. Thus, GPA clearly acts to stimulate neuronal growth and, in so doing, has a permissive effect on the response of CG neurons to CSA.

GPA and CSA in normal $K^{+}$. The effects of GPA and CSA were usually tested on neurons grown in simple medium containing $25 \mathrm{~mm} \mathrm{~K}{ }^{+}$. The elevated $\mathrm{K}^{+}$concentration was not necessary, however, for the stimulatory 
T'ABLE' II

Stimulation of neuronal growth by GPA

Neurons were grown for 9 days either in hasal conditions alone (control) or supplemented with 5\% (v/v) pool 2 from Figure 4 (GPA) and then were assayed for CAT activity, LDH activity, relative rates of protein synthesis, and mean cell volume. Values indicate the mean \pm SEM; $n$ indicates the number of cultures assayed, except for cell volume data where it indicates the number of cells measured.

\begin{tabular}{|c|c|c|c|c|}
\hline $\begin{array}{l}\text { Culture } \\
\text { Medium }\end{array}$ & $\begin{array}{c}\text { CAT } \\
\text { Activity }\end{array}$ & $\begin{array}{l}\text { LDH } \\
\text { Activity }\end{array}$ & $\begin{array}{l}\text { Protein } \\
\text { Synthesis }\end{array}$ & $\begin{array}{c}\text { Cell } \\
\text { Volume }\end{array}$ \\
\hline & \multicolumn{2}{|c|}{ units/culture } & cpm/culture & $\mu m$ \\
\hline Control & $\begin{array}{c}1.57 \pm 0.13 \\
\quad(n=7)\end{array}$ & $\begin{array}{c}0.053 \pm 0.002 \\
(n=8)\end{array}$ & $\begin{array}{c}15,200 \pm 2,100 \\
(n=8)\end{array}$ & $\begin{array}{l}999 \pm 77 \\
(n=40)\end{array}$ \\
\hline GPA & $\begin{array}{c}1.62 \pm 0.18 \\
(n=7)\end{array}$ & $\begin{array}{c}0.166 \pm 0.004 \\
(n=9)\end{array}$ & $\begin{array}{c}33,400 \pm 3,700 \\
(n=8)\end{array}$ & $\begin{array}{c}2,961 \pm 806 \\
(n=40)\end{array}$ \\
\hline
\end{tabular}

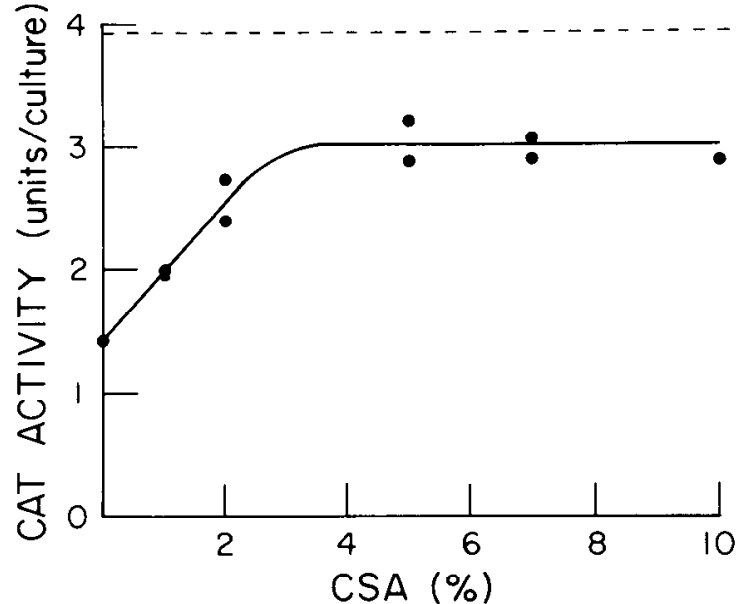

Figure 6. Dependence of CAT levels on CSA concentration. Neurons were grown in basal conditions with the indicated concentrations (v/v) of CSA ( pool 1, Fig. 4) for 9 days and then assayed for CAT activity. Each point represents a single culture. The dotted line indicates the level of CAT activity obtained with $5 \%(\mathrm{v} / \mathrm{v})$ eye extract. Cultures receiving 0 and $10 \% \mathrm{CSA}$ also were assayed for LDH activity and were found to have equivalent amounts.

effects of either GPA or CSA. Even in simple medium with the normal $5.6 \mathrm{~mm} \mathrm{~K} \mathrm{~K}^{+}$, GPA induced $\mathrm{LDH}$ levels greater than that observed for control cultures with 25 mM $\mathrm{K}^{+}$(Table IV). CSA in normal $\mathrm{K}^{+}$also induced an increase in CAT development over that obtained for control cultures with $25 \mathrm{mM} \mathrm{K}^{+}$. For comparative purposes, it would have been desirable to measure CAT and $\mathrm{LDH}$ levels for neurons grown in normal $\mathrm{K}^{+}$without CSA or GPA, but less than half of the neurons survived under such conditions (Fig. 1). Previous results indicated, however, that CAT levels per neuron and overall neuron size in such cultures certainly were not greater than that obtained in $25 \mathrm{mM} \mathrm{K}^{+}$(Nishi, 1980).

Purified mouse NGF was unable to substitute for either GPA or CSA in stimulating the growth and development of CG neurons (Table IV).

\section{Discussion}

Two activities can be distinguished in extracts prepared from embryonic eye tissue that influence the long term fate of CG neurons in culture. One activity, GPA, stimulates growth of the neurons but does not change

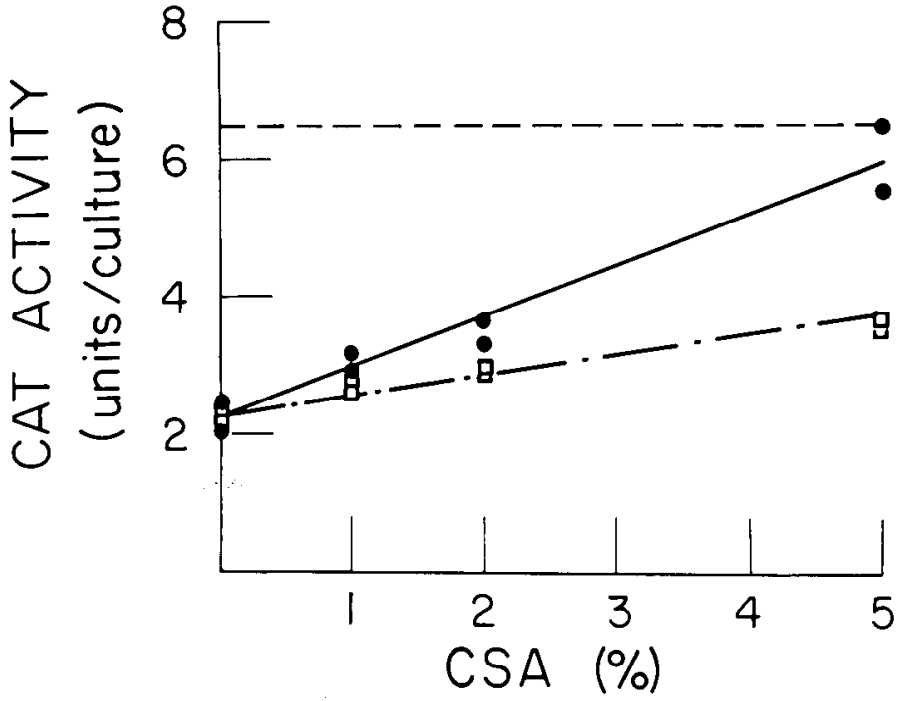

Figure 7. Enhancement of CSA effect by GPA. Neurons were grown for 9 days in basal conditions with the indicated concentrations $(\mathrm{v} / \mathrm{v})$ of CSA supplemented with either $1 \%(\square-\ldots)$ or $5 \%(\mathrm{v} / \mathrm{v})$ GPA and then assayed for CAT activity. Each point represents a single culture. The dotted line indicates the level of CAT activity for cultures grown with $5 \%(\mathrm{v} / \mathrm{v})$ eye extract. GPA was found to have a similar effect on neuronal response to CSA in three other experiments, though full titration curves were not always carried out.

the levels of CAT activity per neuron. The other activity, CSA, stimulates development of CAT activity but does not change the rate of neuronal growth. Since eye tissue contains all of the normal synaptic targets for CG neurons in vivo, it is reasonable to suppose that the stimulatory activities described here may represent components that play a role in the embryo to guide the growth and development of the neurons.

In general terms, the effects of GPA and CSA described here on CG neurons imply a regulatory pattern for parasympathetic neurons that has similarities to the much better characterized pattern for sympathetic neurons. NGF is necessary for the survival and growth of sympathetic neurons, while a second component, present in culture medium conditioned by non-neuronal cells (CM), stimulates at least rat superior cervical ganglion (SCG) neurons to undergo cholinergic development (Patterson, 1978). CM induces a 100- to 1000 -fold increase in CAT levels for rat SCG neurons in culture (Patterson and 
TABLE III

Effects of GPA and CSA on specific activities of CAT

Neurons were grown for 9 days in basal conditions with the indicated supplements at $5 \%(\mathrm{v} / \mathrm{v})$. CAT and $\mathrm{LDH}$ activities were measured on the same cultures and are shown as total units per culture. Values represent individual cultures from the same experiment.

\begin{tabular}{|c|c|c|c|}
\hline Supplement & $\begin{array}{c}\text { CAT } \\
\text { Activity }\end{array}$ & $\begin{array}{c}\text { LDH } \\
\text { Activity }\end{array}$ & $\begin{array}{c}\text { Specific } \\
\text { Activity } \\
\text { (CAT/LDH) }\end{array}$ \\
\hline \multicolumn{4}{|c|}{ units } \\
\hline \multirow[t]{2}{*}{ Eye extract } & 6.65 & 0.205 & 32.4 \\
\hline & 6.30 & 0.192 & 32.8 \\
\hline \multirow[t]{2}{*}{ GPA } & 1.97 & 0.170 & 11.6 \\
\hline & 2.51 & 0.182 & 13.8 \\
\hline \multirow[t]{2}{*}{$\mathrm{CSA}$} & 3.07 & 0.047 & 65.3 \\
\hline & 3.91 & 0.050 & 78.2 \\
\hline \multirow[t]{3}{*}{$\mathrm{GPA}+\mathrm{CSA}$} & 5.57 & 0.172 & 32.4 \\
\hline & 6.50 & 0.182 & 35.7 \\
\hline & 6.70 & 0.190 & 35.3 \\
\hline
\end{tabular}

\section{TABLE IV}

Effects of GPA and CSA in the absence of high $K^{+}$levels

Neurons were grown on a substratum coated with fibroblast material and fed with simple medium and the indicated supplements. After 9 days, the cultures were assayed for CAT and $\mathrm{LDH}$ activities. $\mathrm{K}^{+}$ indicates a final potassium concentration of $25 \mathrm{~mm}$. GPA and CSA were added at $5 \%(\mathrm{v} / \mathrm{v})$. NGF was supplied at $150 \mathrm{ng} / \mathrm{ml}$. Neuronal survival was similar in all cases. Values represent the mean of two to three cultures from the same experiment. Little difference is observed in CAT levels for cultures grown for only 9 days with and without high $\mathrm{K}^{+}$concentrations; greater differences are observed at later times $(\mathrm{R}$. Nishi and D. K. Berg, submitted for publication).

\begin{tabular}{lcc}
\hline Supplements & $\begin{array}{c}\text { LDH } \\
\text { Activity }\end{array}$ & $\begin{array}{c}\text { CAT } \\
\text { Activity }\end{array}$ \\
\hline & \multicolumn{2}{c}{ units/culture } \\
$\mathrm{K}^{+}$ & 0.100 & 1.34 \\
$\mathrm{GPA}$ & 0.152 & 1.24 \\
$\mathrm{GPA}+\mathrm{K}^{+}$ & 0.172 & 1.32 \\
$\mathrm{CSA}$ & 0.104 & 2.79 \\
$\mathrm{CSA}+\mathrm{K}^{+}$ & 0.098 & 2.94 \\
$\mathrm{NGF}+\mathrm{K}^{+}$ & 0.106 & 1.28 \\
\hline
\end{tabular}

Chun, 1977a, b). In the present studies, CSA increased CAT levels for chick CG neurons only 2- to 4-fold. CG neurons were already expressing cholinergic function, however, at the lime they were transferred to culture; their maximum induced level of CAT activity per neuron with CSA was comparable to that obtained for SCG neurons with CM. Clearly, it would be of interest to determine whether CSA induces CAT activity in chick sympathetic neurons and to compare the properties of $\mathrm{CSA}$ and CM when purified.

One interesting feature of GPA action on CG neurons is that it appeared to stimulate all aspects of neuronal growth as reflected by LDH levels, rates of protein synthesis, and soma volume and yet did not increase the levels of CAT activity observed per neuron. It is possible that, in the absence of CSA, the expression of CAT activity by CG neurons is limited by a step that is not influenced by GPA. Alternatively, CAT activity in the absence of CSA may be confined to a subpopulation of neurons that is not responsive to GPA. In the presence of CSA, GPA augmented the levels of CAT per neuron, presumably by increasing the overall synthetic capacity of the neurons.

Several reports have characterized components in tissue extracts or conditioned media that promote the attachment and survival of CG neurons in culture or stimulate the extension of neurites by ciliary ganglion explants. Ebendahl et al. (1979) have described a component from embryonic chick heart that stimulates neurite outgrowth from explants of ciliary, spinal, and sympathetic ganglia. Gel filtration studies indicate the component has an apparent molecular weight of about $4 \times 10^{4}$. Manthorpe et al. (1980) have described a component from embryonic chick eye that enhances the attachment and survival of CG neurons. The component also has an apparent molecular weight of about $4 \times 10^{4}$ by gel filtration. Bonyhady et al. (1980) have described a component from ox heart that promotes survival of CG neurons, and the component has an apparent molecular weight of about $2 \times 10^{4}$ by gel filtration. In the present studies, gel filtration indicated apparent molecular weights of about $2 \times 10^{4}$ for GPA and $5 \times 10^{4}$ for CSA. It should be emphasized that size estimates reported for unpurified components must be considered tentative since the components might be associated with other material in solution. Further studies will be necessary to establish the relationships among these various components.

For the present studies, culture conditions were chosen that permitted the long term maintenance of CG neurons without tissue extracts. GPA and CSA then were characterized as activities that stimulated growth and development beyond that obtained in the control conditions. This approach was chosen to increase the possibility of identifying components that influenced the fate of neurons in vivo, instead of selecting for components that might only provide temporary relief for neurons trying to adapt to cell culture. The conditions used for long term maintenance included culture substrata coated with fibroblast material and culture media containing $25 \mathrm{~mm}$ $\mathrm{K}^{+}$.

It is possible that the fibroblast material provided specific factors similar to those in conditioned medium and tissue extracts that promote survival of CG neurons in vitro. Non-neuronal cells are thought to play important roles in guiding the migration, differentiation, and development of neural crest cells (Weston, 1970; Patterson, 1978). Fixed non-neuronal cells can specifically induce cholinergic development in sympathetic neurons in culture (Hawrot, 1980). Collins (1980) has reported that heart cells deposit material on the substratum that induces the rapid initiation of neurites by CG neurons in culture. Alternatively, the fibroblast effect on CG neurons might have been a relatively nonspecific one in which survival followed as a consequence of enhanced adhesion of the neurons to the substratum. Non-neuronal cells are known to produce microexudate in culture which remains firmly attached to the substratum after washing; the microexudate increases adhesion of the neurons and neuronal processes (Schubert, 1977; Hawrot, 1980).

Elevated $\mathrm{K}^{+}$concentrations have been found to enhance survival and development of a number of neuronal 
populations in culture, including sensory (Scott, 1977), sympathetic (Phillipson and Sandler, 1975), and cerebellar neurons (Lasher and Zagon, 1972). Bennett and White (1979) have described an enhanced survival of CG neurons over a 2-day period in culture when grown in $25 \mathrm{~mm}$ $\mathrm{K}^{+}$. High $\mathrm{K}^{+}$concentrations also have been reported to induce neuronal cell division in culture (Cone and Cone, 1976). No evidence was obtained here for cell division of CG neurons. The number of neurons was the same in 25 $\mathrm{mM} \mathrm{K}^{+}$as in normal $\mathrm{K}^{1}$ with or without eye extract and represented all of the neurons present in the ganglion at the time of dissection; no increase in neuron number was found with culture age. Studies on the influence of high $\mathrm{K}^{+}$concentrations on the growth and development of $\mathrm{CG}$ neurons in eye extract will be described elsewhere ( $R$. Nishi and D. K. Berg, submitted for publication). Elevated $\mathrm{K}^{+}$concentrations were not necessary for the stimulatory effects of GPA and CSA on CG neurons.

The results described here represent a first step toward characterizing the effects of GPA and CSA. It will be important to purify the activities to determine how many components are involved, which tissues produce the components, and which neuronal populations respond to them. Information of this kind should help clarify the significance of these components for neuronal development in vivo.

\section{References}

Bennett, M. R., and W. White (1979) The survival and development of cholinergic neurons in potassium-enriched media. Brain Res. 173: 549-553.

Berg, D. K., and G. D. Fischbach (1978) Enrichment of spinal cord cell cultures with motoneurons. J. Cell Biol. 77: 83-98.

Bonyhady, R., I. A. Hendry, C. Hill, and I. McLennon (1980) Characterization of a cardiac muscle factor required for the survival of cultured parasympathetic neurons. Neurosci. Lett. 18: 197-201.

Burton, L. E., W. H. Wilson, and E. M. Shooter (1978) Nerve growth factor in mouse saliva: Rapid isolation procedures for and characterization of $7 \mathrm{~S}$ nerve growth factor. J. Biol. Chem. 253: 7807-7812.

Cohen, S. (1959) Purification and metabolic effects of a nerve growth-promoting protein from snake venom. J. Biol. Chem. 234: 1129-1137.

Collins, F. (1980) Neurite outgrowth induced by the substrate associated material from non-neuronal cells. Dev. Biol. 79: 247-252.

Cone, C. D., Jr., and C. M. Cone (1976) Induction of mitosis in mature neurons in central nervous system by sustained depolarization. Science 192: 155-158.

Cowan, M. (1973) Neuronal death as a regulative mechanism in the control of cell number in the nervous system. In Development and Aging in the Nervous System, M. Rockstein, ed., pp. 19-41, Academic Press, New York.

Ebendahl, T., M. Belew, C. -O. Jacobson, and J. Porath (1979) Neurite outgrowth elicited by embryonic chick heart: Partial purification of the active factor. Neurosci. Lett. 14: 91-95.

Fischbach, G. D. (1972) Synapse formation between dissociated nerve and muscle cells in low density cell culture. Dev. Biol. 28: 407-429.

Fonnum, F. (1969) Radiochemical micro-assays for the determination of choline acetyltransferase and acetylcholinesterase activities. Biochem. J. 115: 465-472.

Greene, L., and E. Shooter (1980) The nerve growth factor:
Biochemistry, synthesis, and mechanisms of action. Annu. Rev. Neurosci. 3: 353-402.

Hamburger, V., and H. L. Hamilton (1951) A series of normal stages in the development of the chick embryo. J. Morphol. 88: $49-92$.

Hamburger, V., and R. Levi-Montalcini (1949) Proliferation, differentiation, and degeneration in the spinal ganglion of the chick embryo under normal and experimental conditions. J. Exp. Zool. 111: 457-501.

Hawrot, E. (1980) Cultured sympathetic neurons: Effects of cell-derived and synthetic substrate on survival and development. Dev. Biol. 74: 136-151.

Helfand, S. L., G. A. Smith, and N. K. Wessells (1976) Survival and development in culture of dissociated parasympathetic neurons from ciliary ganglia. Dev. Biol. 50: 541-547.

Hollyday, M., and V. Hamburger (1976) Reduction of the naturally occurring motor neuron loss by enlargement of the periphery. J. Comp. Neurol. 170: 311-320.

Landmesser, L., and G. Pilar (1974a) Synaptic transmission and cell death during normal ganglionic development. J. Physiol. (Lond.) 241: 737-749.

Landmesser, L., and G. Pilar (1974b) Synapse formation during embryogenesis on ganglion cells lacking a periphery. J. Physiol. (Lond.) 241: 715-736.

Landmesser, L., and G. Pilar (1978) Interactions between neurons and their targets during in vivo synaptogenesis. Fed. Proc. 37: 2016-2022.

Lasher, J., and R. Zagon (1972) The effect of potassium on neuronal differentiation in cultures of dissociated newborn rat cerebellum. Brain Res. 41: 482-488.

Levi-Montalcini, R., and V. Hamburger (1953) A diffusible agent of mouse sarcoma producing hyperplasia of sympathetic ganglia and hyperneurotization of viscera in the chick embryo. J. Exp. Zool. 123: 233-278.

Lowry, O. H., N. J. Rosebrough, A. L. Farr, and R. J. Randall (1951) Protein measurement with the Folin phenol reagent. J. Biol. Chem. 193: 265-275.

Manthorpe, M., S. Skaper, R. Adler, K. Landa, and S. Varon (1980) Cholinergic neuronotrophic factors: Fractionation properties of an extract from selected chick embryonic eye tissues. J. Neurochem. 34: 69-75.

Nishi, R. (1980) Studies on chick ciliary ganglion neurons developing in cell culture. Doctoral dissertation, University of California, San Diego.

Nishi, R., and D. K. Berg (1977) Dissociated ciliary ganglion neurons in vitro: Survival and synapse formation. Proc. Natl. Acad. Sci. U. S. A. 74: 5171-5175.

Nishi, R., and D. K. Berg (1979) Survival and development of ciliary ganglion neurons grown alone in cell culture. Nature 277: 232-234.

Patterson, P. H. (1978) Environmental determination of autonomic neurotransmitter functions. Annu. Rev. Neurosci. 1: 1-17.

Patterson, P. H., and L. L. Y. Chun (1977a) The induction of acetylcholine synthesis in primary cultures of dissociated rat sympathetic neurons. I. Effects of conditioned medium. Dev. Biol. 56: 263-280.

Patterson, P. H., and L. L. Y. Chun (1977b) The induction of acetylcholine synthesis in primary cultures of dissociated rat sympathetic neurons. II. Developmental aspects. Dev. Biol. 60: 473-480.

Phillipson, O., and M. Sandler (1975) The influence of NGF, potassium depolarization and dibutyryl (cyclic) AMP on explant cultures of chick sympathetic ganglia. Brain Res. 90: 273-281.

Schrier, B. K., and L. Schuster (1967) A simplified radiochemical assay for choline acetyltransferase. J. Neurochem. 14: 977-985. 
Schubert, D. (1977) The substrate attached material synthesized by clonal cell lines of nerve, glia, and muscle. Brain Res. 132: 337-346.

Scott, B. S. (1977) The effects of elevated potassium on the time course of neuron survival in cultures of dissociated dorsal root ganglia. J. Cell. Physiol. 91: 305-316.

Tuttle, J., J. Suszkiw, and M. Ard (1980) Long term survival and development of dissociated parasympathetic neurons in culture. Brain Res. 183: 161-180.

Varon, S., J. Nomura, and E. M. Shooter (1967) The isolation of the mouse nerve growth factor protein in a high molecular weight form. Biochemistry 6: 2202-2209.
Varon, S., J. Nomura, and E. M. Shooter (1968) Reversible dissociation of the mouse nerve growth factor protein into different subunits. Biochemistry 7: 1296-1303.

Varon, S., M. Manthorpe, and R. Adler (1979) Cholinergic neuronotrophic factors. I. Survival, neurite outgrowth and choline acetyltransferase activity in monolayer cultures from chick embryo ciliary ganglia. Brain Res. 173: 29-45.

Weston, J. A. (1970) The migration and differentiation of neural crest cells. Adv. Morphog. 8: 41-114.

White, H. L., and C. J. Cavallito (1970) Inhibition of bacterial and mammalian choline acetyltransferases by styrylpyridine analogues. J. Neurochem. 17: 1579-1589. 